Gut, 1987, 28, 1489-1494

\title{
Screening by colonoscopy for colonic epithelial dysplasia in inflammatory bowel disease
}

\author{
A P MANNING, O R BULGiM, M F DIXON, AND A T R AXON \\ From the Gastroenterology Unit, General Infirmary at Leeds and Department of Pathology, University of \\ Leeds, Leeds
}

SUMMARY We report the results of a prospective study of screening for colorectal epithelial dysplasia by regular colonoscopy in patients with longstanding, extensive colitis (DET group: 112 patients, 366 colonoscopies) together with the findings in all other patients with colitis who have undergone colonoscopy in our unit (non-DET group: 77 patients, 196 colonoscopies). Thirty six DET patients had dysplasia on at least one examination: two patients with high grade dysplasia (HGD) were colonoscoped on suspicion of carcinoma, one asymptomatic patient had HGD at first colonoscopy and one patient had HGD on his sixth colonoscopy, all having carcinomas resected at surgery; the remainder had low grade dysplasia (LGD). Of the DET patients, 100 constituted an ongoing surveillance group (354 colonoscopies) in which LGD was common, being seen on at least one occasion in $33 \%$ of patients $(16.4 \%$ of examinations), but HGD was noted only once with a Dukes A cancer found at surgery. Six non-DET patients had dysplasia diagnosed, this being LGD in all. Even in a carefully selected group of colitics the incidence of HGD is low, but its detection may enable the removal of a colorectal carcinoma at an early and curable stage.

Patients with longstanding, extensive ulcerative colitis (UC) have an increased risk of colorectal carcinoma. ${ }^{1-3}$ The recognition of this association led in the 1960's to the practice of 'prophylactic' proctocolectomy for patients with extensive UC of 10 or more years duration. ${ }^{45}$ Because of the observation that invasive carcinoma may be accompanied, or even preceded, by mucosal changes termed precancer or dysplasia, ${ }^{67}$ however, routine 'prophylactic' proctocolectomy has been largely abandoned in favour of regular colonic or rectal examinations with multiple biopsy. ${ }^{-11}$ Although this 'surveillance' approach has been widely embraced, the epidemiology and significance of mucosal dysplasia in UC is poorly understood. As such an understanding is crucial to the development of an effective management policy for patients with UC, a prospective study was begun at this hospital in 1978 in which patients with longstanding, extensive colitis undergo annual colonoscopy for the detection of dysplasia and

Address for correspondence: Dr A P Manning, Gastrocnterology Unit, The General Infirmary. Leeds LSI 3FX.

Received for publication 9 April 1987. carcinoma. Preliminary results were published in $1980 .{ }^{9}$ We have now analysed the results of this study to the end of 1984 , together with the findings at colonoscopy of all other patients with colonic inflammatory bowel disease to determine the prevalence and clinical associations of mucosal dysplasia in our patient population.

\section{Methods}

PATIENTS

At the Gastroenterology Unit, General Infirmary at Leeds, since 1978 we have colonoscoped regularly, usually annually, all patients with colitis of eight years duration or longer in whom colonic involvement is known to be extensive or total to screen for dysplasia or carcinoma. In addition other patients with colitis have undergone colonoscopy for a variety of clinical indications, biopsies usually being taken to clarify diagnosis or to determine extent of disease. Information on all these patients up to the end of 1984 was obtained from departmental records and supplemented by case note review. 
Colonoscopy was usually carried out under light sedation after a standard laxative and enema bowel preparation. Biopsy specimens were taken with standard forceps from flat mucosa at approximately 8 to $10 \mathrm{~cm}$ intervals along the colon and rectum and also from any identifiable mass lesions. The biopsies were mounted on filter paper before being fixed in formalin and processed by routine techniques. They were sectioned at three levels, stained with haematoxylin and eosin and examined by a single pathologist with an interest in gastrointestinal pathology. For the purpose of this study, only samples with definite dysplasia were recorded and divided into low (LGD) and high grade dysplasia (HGD) using criteria which correspond to those recently put forward by an international study group. ${ }^{\prime 2}$

\section{Results}

\section{PATIENT GROUPS}

Of 189 patients with colitis who had undergone colonoscopy, 112 had had their disease for eight years or longer in duration, which was extensive or total by at least one of (a) barium enema (b) colonoscopic appearances (c) colonic histology (DET group); 77 had colitis of less than eight years' duration and/or disease that was not extensive or total by any criterion (non-DET group). The characteristics of the two groups are shown in Table 1 . The 112 patients in the DET group had undergone 366 colonoscopies, nine having had a further 13 examinations before the duration of their disease had reached eight years. The non-DET group had undergone 106 colonoscopies including the 13 examinations on subsequent DET group patients.

\section{DYSPLASIA}

Of the 189 patients, 42 had dysplasia on at least one occasion (Table 2), 36 being in the DET group and six in the non-DET group $\left(\chi^{2}=14 \cdot 5 ; \mathrm{p}<0 \cdot(01)\right.$.

Of the 36 with dysplasia in the DET group, two patients (patients 6 and 36) underwent colonoscopy

Table 1 Characteristics of patients with colitis undergoing colonscopy

\begin{tabular}{lll}
\hline & $\begin{array}{l}\text { DET group } \\
(n=I 12)\end{array}$ & $\begin{array}{l}\text { Non-I)ET } \\
\text { group }(n=77)\end{array}$ \\
\hline Malc:female & $57: 55$ & $36: 41$ \\
Age at onset (yr) (mean $\pm S D)$ & $29 \cdot 3 \pm 11 \cdot 2$ & $38 \cdot 1 \pm 16 \cdot 7$ \\
Diagnosis: & 98 & 50 \\
$\quad$ Ulcerative colitis & 5 & 12 \\
$\quad$ Crohn's discase & 9 & 15 \\
'Indeterminate' idiopathic colitis & &
\end{tabular}

DET $=$ colitis $>$ e cight years in Duration and Extensive or Total: non-DET = colitis $<$ eight years and/or not extensive or total.
Table 2 Dysplasia patients: presence of dysplasia in colonoscopies performed 1978-1984

\begin{tabular}{|c|c|c|c|c|c|c|c|c|c|}
\hline \multirow[b]{2}{*}{ Paticht } & \multirow[b]{2}{*}{$t$ Group } & \multirow[b]{2}{*}{ Diagnosis } & \multicolumn{7}{|c|}{ Year of colonoscopy } \\
\hline & & & 1978 & 1979 & 1980 & 1281 & 1982 & 1983 & lost \\
\hline 1 & SG & UC & & 11 & 0 & $+(0)^{\prime}$ & 11 & & () \\
\hline 2 & SG & UC & & (1) + & + & 0 & & + & $t+$ \\
\hline 3 & $\mathrm{SG}$ & U' & 0 & () & 0 & + & () & () & () \\
\hline 4 & SG & US & & & & & & $t$ & \\
\hline 5 & $S G$ & Indet. & & + & + & & & & \\
\hline 6 & $\mathrm{SG}$ & UC & $(++)^{2}$ & 0 & + & + & 11 & & 0 \\
\hline 7 & SG & UC & & & & & + & + & + \\
\hline 8 & $S G$ & UC & & & & & & & + \\
\hline 9 & $\mathrm{SG}$ & Indet. & & & & & & & + \\
\hline 10 & $\mathrm{SG}$ & UC & & & & () & () & + & () \\
\hline 11 & $\mathrm{SG}$ & UC' & & () & () & & + & + & 0 \\
\hline 12 & $\mathrm{SG}$ & UC & & & () & () & + & + & 0 \\
\hline 13 & SG & UC & 0 & 0 & () & + & 0 & & 0 \\
\hline 14 & SG & UC & () & & + & + & + & + & 0 \\
\hline 15 & SG & Crohn's & & + & 0 & + & 0 & () & 0 \\
\hline 16 & $\mathrm{SG}$ & UC & & 0 & () & + & () & () & \\
\hline 17 & $\mathrm{SG}$ & UC & & () & () & 0 & 0 & () & $(1)+$ \\
\hline 18 & $\mathrm{SG}$ & UC & & () & () & + & 0 & 0 & \\
\hline 19 & $\mathrm{SG}$ & UC' & 0 & 0 & & 0 & + & & 0 \\
\hline 20 & $\mathrm{SG}$ & UC' & & () & + & + & 0 & () & 0 \\
\hline 21 & SG & UC & & & 0 & + & & 0 & 0 \\
\hline 22 & $\mathrm{SG}$ & UC' & & 0 & 0 & + & $+1+$ & 0 & 0 \\
\hline 23 & SG & UC & & 0 & () & + & + & () & 0 \\
\hline 24 & $\mathrm{SG}$ & UC & & 0 & & + & + & + & + \\
\hline 25 & $\mathrm{SG}$ & UC & & & & & 0 & + & () \\
\hline 26 & $\mathrm{SG}$ & Crohn's & & + & 0 & & () & & \\
\hline 27 & SG & UC & & & + & + & + & + & 0 \\
\hline 28 & SG & UC & & & () & 0 & 0 & + & 0 \\
\hline 29 & SG & UC & 0 & & 0 & 0 & + & + & + \\
\hline 30 & $\mathrm{SG}$ & UC & & () & + & 0 & 0 & () & 0 \\
\hline 31 & $\mathrm{SG}$ & U' & & & 0 & 11 & + & + & 0 \\
\hline 32 & $S G$ & U' & & 0 & + & 0 & & 0 & \\
\hline 33 & $\mathrm{SG}$ & UC & & & & & & & + \\
\hline 34 & DET & UC & & & & & & & $+t$ \\
\hline 35 & DET & UC & & & + & & & & \\
\hline 36 & DET & UC & ++ & & & & & & \\
\hline 37 & non-DE & Crohn's & & & & & & + & \\
\hline 38 & non-DE & UC & & + & & & & & \\
\hline 39 & non-DE & U UC & & & & & & & + \\
\hline 40 & non-DE' & 'UC' & & & & + & & & \\
\hline 41 & non-DE & UC & & & & + & () & & \\
\hline 42 & non-DE & Uc & & & & & $+1+$ & & \\
\hline
\end{tabular}

DET = colitis > eight years in Duration and Extensive or Total; $\mathrm{SG}=$ DET patients also in the surveillance group; non-DET $=$ colitis< <ight years and/or non extensive or total: $U C^{\circ}=$ ulcerative colitis: Indet = "indeterminate idiopathic colitis: ()$=$ no dysplasia:

$+=$ low grade dysplasia $++=$ high grade dysplasia; $1=$ two

colonoscopies performed within a year indicated thus $-1-$;

$2=$ patient 6 had surveillance colonoscopies after subtotal colectomy for carcinoma initially suspected on Ba enema.

for confirmation of carcinoma suspected on barium enema. Patient 6 had a polypoid lesion in the sigmoid colon both on barium enema and at colonoscopy with HGD on biopsy; patient 36, with a caecal lesion radiologically, had an incomplete colonoscopy but with HGD on biopsies taken from the transverse colon. A carcinoma was subsequently resected surgically in each case. In a further 11 patients 
dysplasia was detected at first colonoscopy; in 10 this was LGD and in one HGD (patient 34). In this asymptomatic patient with colitis of 15 years duration colectomy revealed a Dukes' A carcinoma.

SURVEILIANCE GROUP

Of the 112 patients in the DET group, 13 underwent colectomy after a single colonoscopy, one of whom (patient 6) had subtotal colectomy and subsequent colonoscopies, leaving 100 DET patients who can be regarded as an ongoing surveillance group (SG).

In the surveillance group, a total of 354 examinations had been carried out and the number of colonoscopies per patient is shown in the Figure. Thirty three patients in the surveillance group had dysplasia on at least one occasion, in 59 out of 152 colonoscopies. At 58 examinations the dysplasia was LGD and at one (patient 2) was HGD. This 45 year old man had had UC for 21 years and had Dukes' A carcinoma at surgery; in three of his previous five examinations LGD had been noted. In the 53 examinations where the site of dysplasia had been recorded, the rectum was affected in 32; patient 2 with HGD and carcinoma did not have dysplasia in the rectum either on biopsy or in the surgical specimen. In the 33 surveillance group patients with dysplasia the extent of disease had been determined by modalities including radiology in 23 and by colonoscopy or histology but not radiology in 10 .

The 67 surveillance group patients without dysplasia had undergone 202 colonoscopies. The extent of their disease had been determined by radiology in 40 .

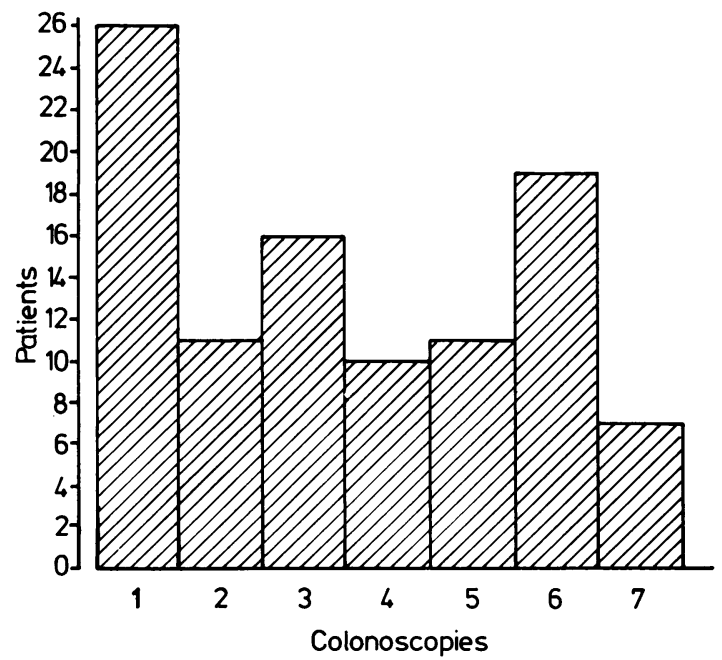

Figure Surveillance group: number of colonoscopies per patient.
In order to assess the prevalence of dysplasia with increasing duration of disease, the number of dysplastic examinations per decade of disease duration in the surveillance group was determined and is shown in Table 3.

\section{COLECTOMY FINDINGS}

In the DET group 17 patients had resective surgery for colitis after colonoscopy. Of these, dysplasia had been diagnosed in five: in two (patients 6 and 36) the colonoscopies had been done with a prior suspicion of carcinoma that was subsequently confirmed; in one (patient 34) HGD was noted at first colonoscopy

Table 3 Incidence of dysplasia according to decade of disease duration in the surveillance group

\begin{tabular}{llllllllll}
\hline $\begin{array}{l}l s t^{*} \\
+\end{array}$ & 0 & $\begin{array}{l}\text { 2nd } \\
+\end{array}$ & 0 & $\begin{array}{l}3 r d \\
+\end{array}$ & 0 & $\begin{array}{l}\text { th } \\
+\end{array}$ & 0 & $\begin{array}{l}5 t h \\
+\end{array}$ & 0 \\
\hline 7 & 61 & 28 & 1.32 & 19 & 78 & 4 & 8 & 1 & 3 \\
$(10 \cdot 3)$ & $(89 \cdot 7)$ & $(17 \cdot 5)$ & $(82 \cdot 5)$ & $(19 \cdot 6)$ & $(80 \cdot 4)$ & $(33 \cdot 3)$ & $(66 \cdot 7)$ & $(25)$ & $(75)$ \\
68 & & 169 & & 97 & & 12 & & 4 & \\
\hline
\end{tabular}

${ }^{*} 1$ st decade $=8-10$ years only in surveillance group; $0=$ no dysplasia: $+=$ dysplasia: ()$=\%$.

and carcinoma resected; in one (patient 2) HGD was noted during surveillance and carcinoma resected; one patient (patient 35) had LGD at first colonoscopy after 11 years of disease but no dysplasia was seen in the colectomy specimen. Of those without a preoperative diagnosis of dysplasia, two patients had colectomy after a single non-dysplastic colonoscopy and LGD was seen. Only three surveillance group patients had surgical resection during surveillance, in one case this being for HGD with carcinoma being found in the resected specimen (patient 2).

In the non-DET group, six patients of 77 showed dysplasia, all LGD. Three of these (patients 38, 40, and 42) had surgery subsequently for failed medical management with no dysplasia noted in the resected specimens.

\section{Discussion}

It is widely accepted that longstanding colitis increases the risk of colorectal cancer. It is likely that the magnitude of this risk increases with time and certainly does not become significant until disease has been present in most of the colon for eight to 10 years. ${ }^{1-3.13}$ It is also possible too that the risk varies geographically ${ }^{14}$ so that estimates of cancer risk from the literature may need to be interpreted with caution. The practice of total removal of the colon and rectum at a stage when the risk of cancer was 
formerly regarded as significant was obviously successful in preventing the development of most invasive neoplasms but was unacceptable to many patients, especially those in whom colitis was in remission or causing few symptoms. The observation that recognisable histological abnormalities, termed dysplasia or precancer, could be seen in mucosa distant from a carcinoma in colitis raised the hope that regular screening of the mucosa for these abnormalities could predict the onset of carcinoma, ${ }^{67}$ thus restricting colectomy to those patients whose colonic mucosa was developing invasive potential. This has lead to many units setting up surveillance programmes for screening colitics thought to be at increased risk by colonoscopy and multiple biopsy at regular intervals. The validity of this surveillance approach can only be assessed by observations on large groups of at risk patients examined regularly for the purpose of detecting dysplasia or cancer. The few published reports from such programmes are difficult to compare, however, because of varying country of origin, criteria for patient selection, colonoscopic technique, frequency of examinations and pathological interpretation. ${ }^{-1115}$ Our series constitutes a well defined group of colitics examined by standard techniques in which dysplasia has been sought by a single pathologist.

The two patients (numbers 6 and 36 ) in whom HGD was found at colonoscopy carried out because of clinical and radiological suspicion of cancer do not relate to the role of colonoscopic surveillance in UC. They were both examined early in 1978 when barium enema was commonly used by some clinicians at this hospital in the continuing follow up of patients with colitis. This is no longer our routine practice. The patient (number 34) in whom HGD was seen at first colonoscopy after 15 years of disease with cancer found at surgery is of some interest as the colonoscopy was carried out solely for surveillance purposes although the duration of his dysplastic mucosa cannot be determined. It is consideration of the surveillance group, however, that is the main purpose of this report. Here LGD was common, being seen on at least one occasion in $33 \%$ of patients $(16.4 \%$ of examinations) but HGD was noted only once with an associated cancer found at surgery. The surveillance programme did not prevent the development of cancer in this patient but enabled its resection at an asymptomatic and curable stage by suggesting surgery on the basis of HGD. This patient had multiple inflammatory polyps and it had been felt by the colonoscopist that the dysplastic biopsy had been taken from such a lesion. In the resected specimen, however, the polypoid adenocarcinoma could be distinguished from surrounding inflammatory polyps. It is accepted in the literature that when dysplasia, even LGD, is associated with a colonoscopically visible lesion the chances of a coexisting cancer are greater. ${ }^{16}{ }^{17}$ In our unit during the surveillance programme the identification of a colonoscopic 'dysplasia association lesion or mass' has been infrequent. Obviously this could be because of its being uncommon in our patients or to a failure of the endoscopist to recognise it, especially in the presence of multiple inflammatory polyps. No malignancy has become clinically apparent, however, as a result of such a lesion being overlooked. This emphasises the importance of biopsy of all raised lesions in colitics, even those assumed to be inflammatory. "t

Our series comprised mainly UC patients although Crohn's disease of the colon and 'indeterminate' idiopathic inflammatory bowel disease were represented. Cancer and HGD were only seen in UC patients but LGD was observed in all three groups. there being no statistically significant difference in the distribution between them $\left.\left(\chi^{2}=3.598 ; p>0\right) \cdot 1\right)$. Nevertheless, patients with longstanding Crohn's colitis have developed colon cancer ${ }^{1 \times 1 "}$ and epithelial dysplasia has been reported in this disease. ${ }^{211} 21$ It is therefore not surprising that they are represented in our dysplastic group. The finding of dysplasia emphasises the importance of including these patients in any surveillance programme.

There is little information on the development of dysplasia over a period of time. Available data from the literature suggest that the risk of carcinoma increases with the passage of time, "becoming significant after eight to 10 years of extensive disease. Hanauer et $l^{22}$ have suggested that the prevalence of dysplasia increases over the years with $90 \%$ of patients having dysplasia after 37 years of disease; it is unclear upon how many patients this figure is based. Our analysis, in terms of examinations per decade of disease shows that, although there is a trend, there is no significant increase in the incidence of dysplasia with time. In common with other series, however, ${ }^{3} 12^{12}: 3$ this assessment is hampered by small numbers in the groups with longer duration of disease.

Dysplasia was significantly more common in the DET group which was selected on the basis of accepted risk for malignancy - extensive or total disease for greater than eight years. Dysplasia was noted in six patients from the non-DET group, however. In all these patients dysplasia was low grade. It is apparent that even in patients with less extensive or shorter duration disease, dysplasia can occur albeit infrequently; indeed, one retrospective series has suggested an increased risk of cancer in left sided colitis after 20 years of disease. ${ }^{.3}$ It is likely, however, that the incidence is not great enough to warrant screening of all colitics irrespective of 
duration and extent. The means of determining extent of disease may be an important variable in patient selection. In the older series, where the group of colitics at increased risk were characterised, extent of disease was assessed by radiology, usually single contrast barium enema. It is accepted, however, that inflammation may be more extensive than indicated radiologically and is more accurately determined by colonoscopy and even more so by histology. ${ }^{24}$ In our surveillance group extent of disease was not always determined by radiology. There was no significant difference, however, in the proportion of patients with dysplasia in those groups with or without radiology as the means of assessing extent of disease.

The distribution of dysplasia was variable both within a single examination and over time in the individual patient. The failure to detect dysplasia in successive colonoscopies may be because of sampling error as careful study of resection specimens has revealed patchy distribution in many cases. ${ }^{25}$ Of more importance are inconsistencies in histological interpretation. A recently completed interobserver study (in preparation) revealed considerable disagreements over the diagnosis of dysplasia versus non-dysplasia, the conditional probability of agreement for low grade dysplasia being $(0 \cdot 52$. This means that in this particular study the chance of one pathologist randomly selected from a panel agreeing with a first observer's diagnosis of low grade dysplasia was only $52 \%$. Even when the biopsies are examined by the same pathologist, as in our study, there will be intraobserver variation in the diagnosis of LGD particularly in the presence of active inflammation and regeneration where 'reactive hyperplasia' is a source of confusion.'2 Thus we believe that the intermittent finding of LGD in sequential colonoscopies may have as much to do with observer variation as with sampling errors.

In conclusion, even in a highly selected group of colitics at increased risk of colon cancer, HGD was detected in only one of 354 colonoscopies on 100 patients, this in association with a Dukes' A adenocarcinoma. While there are difficulties in the recognition of LGD, it was found more commonly in longstanding colitics with extensive disease no matter how the extent was determined, and uncommonly in less extensive or short duration disease. Progression from low grade to high grade dysplasia, however, would appear to be an infrequent phenomenon being documented in only one instance in 125 patient years of follow up since first diagnosis of LGD. Although the incidence of HGD is low in comparison with the time and expense involved in its detection, such surveillance is worthwhile in that cancer can be detected at an early and curable stage in these relatively young patients.

\section{References}

1 Slaney G. Brooke B. Cancer in ulcerative colitis. Lancet 1959; ii: 694-8.

2 Devroede G, Taylor W. Sauer W, Jackman R, Stickler G. Cancer risk and life expectancy of children with ulcerative colitis. N Engl J Med 1971; 285: 17-21.

3 Lennard-Jones J, Morson B. Ritchie J, Shove D, Williams C. Cancer in colitis: assessment of the individual risk by clinical and histological criteria. Gastroenterology 1977: 73: 1280-9.

4 MacDougall I. The cancer risk in ulcerative colitis. Lancet 1964 ; ii: $655-8$.

5 DeDombal F. Watts J. Watkinson G, Goligher J. Local complications of ulcerative colitis: stricture, pseudopolvposis, and carcinoma of colon and rectum. $\mathrm{Br} \mathrm{Med} \mathrm{J}$ 1966; i: $1442-7$.

6 Morson B. Pang L. Rectal biopsy as an aid to cancer control in ulcerative colitis. Gut 1967; 8: 423-34.

7 Cook M. Goligher J. Carcinoma and epithelial dysplasia complicating ulcerative colitis. Gastroenterology 1975; 68: $1127-36$.

8 Nugent F, Haggitt R, Colcher H, Kutteruf G. Malignant potential of chronic ulcerative colitis. Gastroenterology 1979; 76: $1-5$.

9 Dickinson R, Dixon M, Axon A. Colonoscopy and the detection of dysplasia in patients with longstanding ulcerative colitis. Lancet 1980); ii: 620-2.

10 Lennard-Jones J, Morson B, Ritchic J, Williams C. Cancer surveillance in ulcerative colitis. Lancet 1983; ii: $149-52$

11 Rosenstock E, Farmer R, Petras R. Sivak M, Rankin G, Sullivan B. Surveillance for colonic carcinoma in ulcerative colitis. Gastroenterology 1985; 89: 1342-6.

12 Riddell R. Goldman H, Ransohoff D, et ai. Dysplasia in inflammatory bowel disease: standardised classification with provisional clinical applications. Hum Pathol 1983; 14: 931-68.

13 Devroede G. Taylor W. On calculating cancer risk and survival of ulcerative colitis patients with the life table method. Gastroenterology 1976; 71: 505-9.

14 Riddell R. Cancer and dysplasia in ulcerative colitis: an insoluble problem? Prog Clin Biol Res 1985; 186: 77-90.

15 Katzka I, Brody R, Morris E, Katz S. Assessment of colorectal cancer risk in patients with ulcerative colitis: experience from a private practice. Gastroenterology 1983; 85: 22-9.

16 Blackstone $M$, Riddell $R$, Rogers $B$, Lewis $B$. Dysplasia-associated lesion or mass (DALM) detected by colonoscopy in long-standing ulcerative colitis: an indication for colectomy. Gastroenterology 1981; 80: $366-74$.

17 Butt J, Korishi F, Morson B, Lennard-Jones J, Ritchie J. Macroscopic lesions in dysplasia and carcinoma complicating ulcerative colitis. Dig Dis Sci 1983; 28: $18-26$.

18 Korelitz B. Carcinoma of the intestinal tract in Crohn's disease: results of a survey conducted by the National Foundation of Ileitis and Colitis. Am J Gastroenterol 1983; 78: 44-6.

19 Greenstein A, Sachar D, Smith H, Janowitz H, Aufses 
A. A comparison of cancer risk in Crohn's disease and ulcerative colitis. Cancer 1981; 48: 2742-5.

20) Craft C, Mendelsohn G, Cooper H, Yardley J. Colonic 'precancer' in Crohn's disease. Gastroenterology 1981: 80: $578-84$.

21 Simpson S, Traube J, Riddell R. The histologic appearance of dysplasia (precarcinomatous change) in Crohn's disease of the small and large intestine. Gastroenterology 1981; 81: 492-501.

22 Hanauer S, Riddell R, Kirsner J, Levin B. Life-table analysis of onset of dysplasia in colonic ulcerative colitis. Gastroenterology 1983; 84: 1181.

23 Greenstein A, Sachar D, Smith H, et al. Cancer in universal and left sided ulcerative colitis: factors determining risk. Gastroenterology 1979; 77: 29()-4.

24 Dilawari J, Parkinson C. Riddell R, Loose H, Williams C. Colonoscopy in the investigation of ulcerative colitis [Abstract]. Gut 1973; 14: A426.

25 Ransohoff D, Riddell R, Levin B. Ulcerative colitis and colonic cancer. Problems in assessing the diagnostic usefulness of mucosal dysplasia. Dis Colon Rectum 1985; 28: 383-8.

26 Allen D, Biggart J. Pyper P. Large bowel mucosal dysplasia and carcinoma in ulcerative colitis. $J$ Clin Pathol 1985; 38: 30-43. 